\title{
The fate of pancreatic tumor cell lines following p16 overexpression depends on the modulation of CDK2 activity
}

\author{
J Calbó ${ }^{1,3}$, C Serna ${ }^{1}$, J Garriga ${ }^{2}$, X Graña ${ }^{2}$ and A Mazo, \\ 1 Department of Biochemistry and Molecular Biology, University of Barcelona, \\ Avda. Diagonal 645, Barcelona 08028, Spain \\ 2 Department of Biochemistry, Fels Institute for Cancer Research and Molecular \\ Biology, Temple University School of Medicine. 3307 North Broad St., \\ Philadelphia, PA19140, USA \\ ${ }^{3}$ Current address: Division of Molecular Genetics, Netherlands Cancer Institute, \\ Plesmanlaan 121, 1066 CX Amsterdam, The Netherlands \\ * Corresponding author: A Mazo, Department of Biochemistry and Molecular \\ Biology, University of Barcelona, School of Biology, Avda. Diagonal 645, \\ Barcelona 08028, Spain. Tel.: + 34-93-402-12-10; Fax: +34-93-402-12-19; \\ E-mail: adela@bq.ub.es
}

Received 07.3.04; revised 07.4.04; accepted 17.5.04; published online 13.8.04 Edited by M Blagosklonny

\begin{abstract}
Restitution of lost tumor-suppressor activities may be a promising strategy to target specifically cancer cells. However, the action of ectopically expressed tumor-suppressor genes depends on genetic background of tumoral cells. Ectopic expression of $\mathrm{p} 16^{\mathrm{INK} 4 a}$ induces either cell cycle arrest or apoptosis in different pancreatic cancer cell lines. We examined the molecular mechanisms mediating these two different cellular responses to p16 overexpression. Ectopic expression of p16 leads to G1 arrest in NP-9 cells by redistributing p21/p27 CKls and inhibiting cyclin-dependent kinase CDK2 activity. In contrast, in NP-18 cells cyclin E (CycE)/ CDK2 activity is significantly higher and is not downregulated by p16-mediated redistribution of p21/p27. Moreover, inhibition of CDK4 activity with fascaplysine, which does not affect CycE/ CDK2 activity, reduces pocket protein phosphorylation in both cell lines, but fails to induce growth arrest. Like overexpression of p16, fascaplysine induces apoptosis in NP-18 cells, suggesting that inhibition of $D$-type cyclin/CDK activity in cells with high levels of CycE/CDK2 activity activates an apoptotic pathway. Inhibition of CycE/CDK2 activity via ectopic expression of p21 in NP-18 cells overexpressing p16 induces growth arrest and prevents p16-mediated apoptosis. Accordingly, silencing of p21 expression by using small interfering RNA switches the fate of p16-expressing NP-9 cells from cell cycle arrest to apoptosis. Our data suggest that, after CDK4/6 inactivation, the fate of pancreatic tumor cells depends on the ability to modulate CDK2 activity.

Cell Death and Differentiation (2004) 11, 1055-1065.

doi:10.1038/sj.cdd.4401481

Published online 13 August 2004
\end{abstract}

Keywords: $\mathrm{p} 16^{\text {INK4a; }}$ cyclin-dependent kinase; pocket proteins; p27/p21; apoptosis

\begin{abstract}
Abbreviations: $\mathrm{CKI}$, cyclin-dependent kinase inhibitor; CDK, cyclin dependent kinase; siRNA, small interference RNA; MEF, mouse embryo fibroblast; cDNA, complementary DNA; MOI, multiplicity of infection; PARP, poly-ADP-ribose polymerase; PFU, plaque forming unit; wt, wild-type; Cyc, cyclin
\end{abstract}

\section{Introduction}

$\mathrm{p} 16^{\text {INK4a }}$ is a tumor-suppressor gene frequently lost in a number of malignancies through homozygotic deletion, point mutation or methylation-mediated gene silencing (reviewed in Ruas and Peters $\left.{ }^{1}\right)$. In addition, $\mathrm{p} 16^{\text {INK4a }}$ inactivation is linked to familial melanoma and pancreatic hereditary adenocarcinoma. ${ }^{2,3}$ The absence of $\mathrm{p} 16$ predisposes mice to tumorigenesis. ${ }^{4,5}$

The product of $\mathrm{p} 16^{\mathrm{INK} 4 a}$ gene is a cyclin D-dependent kinase (CDK4 and CDK6) inhibitor, which arrests cell cycle progression in the G1 phase in a pRB-dependent manner. ${ }^{6-8}$ Initially, it was described that p16-mediated inhibition of CDK4/6 and the subsequent activation of pRB was sufficient to drive cells into a quiescent state (reviewed in Sherr and Roberts ${ }^{9}$ ). However, recent results using $\mathrm{p} 107^{-1-} / \mathrm{p} 130^{-l-}$ MEFs have demonstrated that in addition to $\mathrm{pRB}, \mathrm{p} 16$ growthinhibitory activity depends on the presence of either p107 or p130. ${ }^{10}$ While p16 induces inhibition of CDK4/6 activity and growth arrest, inhibition of CDK4 activity using a dominantnegative CDK4 mutant does not result in growth arrest. ${ }^{11}$ In agreement with these results, it has been shown that p16mediated disruption of CDK4/6 active complexes results in redistribution of the CDK inhibitors (CKIs) p21 ${ }^{\text {Cip1 }}$ and p27 ${ }^{\text {Kip } 1}$ (reviewed in Sherr and Roberts ${ }^{9}$ ). p21/p27 CKIs contribute to the binding and activity of CycD-CDK4/6 complexes, while they are strong inhibitors of CDK2 activity. In keeping with these observations, cyclin $E$ (CycE) overexpression bypasses p16-mediated $\mathrm{G} 1$ arrest $^{12,13}$ and induces DNA synthesis in the absence of D-type cyclin activity and mitogenic stimulation. ${ }^{14,15}$ Thus, p16 upregulation inhibits phosphorylation of pocket protein by both direct and indirect inhibition of G1-CDK activities.

Given its growth-inhibitory function, restoration of $\mathrm{p} 16$ activity might have therapeutic applicability (reviewed in Calbó and $\mathrm{Mazo}^{16}$ ). Adenoviral and retroviral vectors have been used to transfer wt-p16 $6^{\text {INK4a }}$ gene into tumor cells growing in vitro and in vivo. In most studies, ectopic expression of p16 caused cell cycle arrest in pRB-positive cell lines and reduced tumor growth in vivo. However, p16induced apoptosis has also been observed in a number of studies. p16-induced apoptosis resulted from the activation of p53-dependent apoptotic pathways $\left({ }^{17-21}\right.$, reviewed in Calbó and $\mathrm{Mazo}^{16}$ ), including bcl-2 downregulation and activation of caspases in non-small-cell lung cancer cells. ${ }^{17,18}$ Interestingly, ectopic expression of p16 also induced apoptosis in 
p53-deficient cell lines, implicating a p53-independent apoptotic pathway. ${ }^{20}$ Taken together, these results indicate that the effects of $\mathrm{p} 16$ on tumor cells depend on the genetic alterations acquired during transformation and tumor progression. Given that apoptosis induction might yield higher therapeutic activity than induction of growth arrest, it is important to understand the molecular features that determine different cell fates after p16 reintroduction.

We have previously shown the effects of $p 16$ expression in a panel of pancreatic tumor cell lines. ${ }^{22}$ Three cell lines, NP-9, NP-29 and NP-31, undergo cell cycle arrest and are driven to a senescence-like state following ectopic expression of p16. All three cell lines are p16 deficient and pRB-wt. In contrast, NP-18 cells ( $p 16-w t, p R B-w t)$ are resistant to $p 16$-induced cell cycle arrest and senescence. Intriguingly, cell proliferation and tumor growth are reduced in NP-18 cells and tumors ectopically expressing p16, as p16 induces apoptosis. Here, we examine the molecular events that mediate different cell fates in NP-9 and NP-18 pancreatic tumor cells following p16 overexpression. Our results establish a link between genotype and cell fate following restitution of a tumor-suppressor function, which may have important implications in the design of new therapeutic strategies.

\section{Results}

\section{Ectopic expression of $\mathrm{p} 16^{\mathrm{INK} 4 a}$ in pancreatic adenocarcinoma cell lines induces G1 cell cycle arrest or apoptosis}

We have shown previously ${ }^{22}$ that adenovirus-mediated transduction of $\mathrm{p} 16^{I N K 4 a}$ inhibits DNA synthesis and induces G1 cell cycle arrest in NP-9 cells, but fails to do so in NP-18 cells. Instead, ectopic expression of p16 induces apoptosis in
NP-18 cells, as determined by Annexin- $V$ binding and PARP cleavage (Table 1). Since these two cell lines express wildtype $\mathrm{pRB}$ and $\mathrm{pRB}$ is required for $\mathrm{p} 16$-mediated $\mathrm{G} 1$ arrest, we examined the molecular events mediating different responses to p16 overexpression.

To identify potential alterations in cell cycle regulators in NP-9 and NP-18 cells, we used Western blot analysis to measure the expression of proteins involved in $\mathrm{G} 1 / \mathrm{S}$ cell cycle

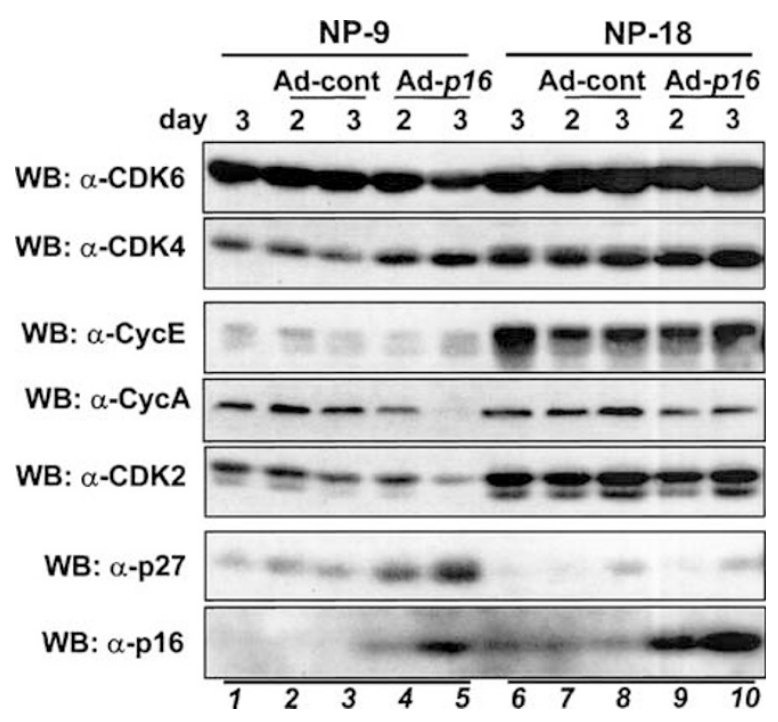

Figure 1 Changes in the expression of several G1 cyclins, CDKs and CKIs upon ectopic expression of p16 in NP-9 and NP-18 cells. NP-9 and NP-18 cells were seeded at low density and infected $24 \mathrm{~h}$ later with Ad-control or Ad-p16 at an $\mathrm{MOI}$ of 50 , or mock infected. Cell lysates were obtained from cells harvested 2 and 3 days after infection, and protein extracts were resolved in 12 and $15 \%$ SDS-PAGE and analyzed by Western blot using specific antibodies against different cyclins, CDKs and CKIs as indicated in Materials and Methods

Table 1 (a) Genetic background of NP-9 and NP-18 cell lines and (b) summary of adenovirus-mediated p16 gene transfer effects on NP-9 and NP-18 cell lines

\begin{tabular}{|c|c|c|c|c|}
\hline & \multicolumn{2}{|c|}{ NP-9 } & \multicolumn{2}{|c|}{ NP-18 } \\
\hline & Status & Exp. levels ${ }^{a}$ & Status & Exp. levels ${ }^{a}$ \\
\hline \multicolumn{5}{|l|}{ (a) } \\
\hline K-ras & GGT-GAT & ND & $w t$ & ND \\
\hline p16 & $11 \mathrm{pb}$ deletion & - & $w t$ & + \\
\hline p53 & 175 CGC-CAC & ++ & 246 ATG-GTG & ++ \\
\hline p21 & $w t$ & \pm & $w t$ & - \\
\hline$p R B$ & $w t$ & + & $w t$ & + \\
\hline Doubling time & \multicolumn{2}{|c|}{$97 \mathrm{~h}$} & \multicolumn{2}{|c|}{$36 \mathrm{~h}$} \\
\hline & \multicolumn{2}{|c|}{ NP-9 } & \multicolumn{2}{|c|}{ NP-18 } \\
\hline & Ad-control & Ad-p16 & Ad-control & Ad-p16 \\
\hline \multicolumn{5}{|l|}{ (b) } \\
\hline G1 population (\%) & 57.9 & 86.1 & 53.1 & 48.9 \\
\hline S population $(\%)^{\mathrm{c}^{\prime}}$ & 13.8 & 1.7 & 20.2 & 19.8 \\
\hline Annexin-V (\%) ${ }^{\mathrm{d}^{\prime}}$ & 3.7 & 4.1 & 8.0 & 28.6 \\
\hline Senescence (SA- $\beta$-gal) ${ }^{\mathrm{e}}$ & - & +++ & - & - \\
\hline Growth inhibition (\%) ${ }^{\dagger}$ & \multirow{2}{*}{\multicolumn{2}{|c|}{$\begin{array}{c}66 \\
\text { Senescence }\end{array}$}} & \multirow{2}{*}{\multicolumn{2}{|c|}{$\begin{array}{c}85 \\
\text { Apoptosis }\end{array}$}} \\
\hline Cell destination after p16 expression & & & & \\
\hline
\end{tabular}

${ }^{a}$ Expression levels determined by Western blot. wt, wild type; ND, not determined ${ }^{b} \mathrm{G} 1$ population determined by flow-cytometry analysis of PI-stained cells. ${ }^{\mathrm{c}} \mathrm{S}$-phase population determined by flow-cytometry analysis of $5 \mathrm{BrdU}$ incorporation. ${ }^{\mathrm{d}}$ Apoptotic cells determined as Annexin-V-positive, PI-negative, by flow-cytometry analysis. ${ }^{\mathrm{e}}$ Detection of senescence-associated acidic $\beta$-galactosidase activity 6 days after adenovirus infection. ${ }^{\mathrm{f} P e r c e n t a g e}$ of growth inhibition at day 8 after Ad-p16 with respect to Ad-control infection, measured by cell counting. Adapted from Calbó et al ${ }^{22}$ 
control (Figure 1). To this end, exponentially growing cells were infected with Ad-p16, Ad-control or mock infected as described in the Materials and Methods section. At the time points indicated, cells were collected and whole protein extracts were subjected to SDS-PAGE followed by Western blot analysis using specific antibodies. Basal levels of CDK4, CDK6, CDK2 and, in particular, CycE were higher in NP-18 than in NP-9 exponentially growing cells. While ectopic expression of p16 in NP-9 cells induced a decrease in the levels of CycA, CDK2 and, to a lesser extent, CycE, and an increase in the levels of p27, comparable ectopic expression of 16 in NP18 cells had little or no effect on the expression of these proteins.

\section{Reorganization of cyclin-CDK complexes}

Next, we determined whether $\mathrm{p} 16$ induced differential redistribution of the subunits of G1/S cyclin-CDK complexes by immunoprecipitating them and determining their subunit composition by Western blot analysis. CDK6 was associated with CycD1, p27 and p21 in exponentially growing NP-9 cells (Figure 2a, lanes 3-4). Ectopic expression of p16 led to CDK6-p16 binding and abrogation of the complexes mentioned above (Figure 2a, lanes 1-2). In NP-18, however, the CDK6-p16 complex was very abundant, even in Ad-controlinfected cells. Barely detectable levels of p27 and CycD1 were seen bound to CDK6 in control-treated NP-18 cells (Figure $2 a$, lanes 7-8), and these interactions were also abrogated following $p 16$ overexpression (Figure $2 a$, lanes $5-6$ ). Surprisingly, most endogenous p16 appeared complexed to CDK6 and only a fraction of $\mathrm{p} 16$ was detected in association with CDK4 (see below) (Figure 3a). Immunofluorescence experiments showed that CDK6 was ubiquitous in control cells. However, ectopic expression of p16 resulted in shift of the CDK6 signal to the cytoplasm in both NP-9 and NP-18 cells. Newly expressed p16 was detected mostly in the cytoplasm but also in the nucleus (Figure 2b). Analysis of CDK4 complexes in control-infected NP-9 cells revealed binding of CDK4 to CycD1, p27 and p21 (Figure 3). Following p16 expression, formation of $\mathrm{p} 16-\mathrm{CDK} 4$ complexes led to disruption of CDK4 complexes containing CycD1, p27 and p21, although significant amounts of p27 and CycD1 remained bound to CDK4. In NP-18 control-infected cells, only comparatively low levels of p27 were detected in association with CDK4, but this interaction was downregulated following ectopic p16 expression.

Given that the members of Cip/Kip family of CKIs have been reported to act both as positive modulators of D-type cyclindependent CDKs and as potent inhibitors of CDK2, we tested whether the abrogation of CDK6/CDK4-p21/p27 complexes resulted in reorganization of G1-CDK complexes and inhibition of their activities (reviewed in Sherr and Roberts ${ }^{9}$ ). To this end, p27 and p21 were immunoprecipitated, and the immunocomplexes were resolved by SDS-PAGE followed by Western blot analysis with specific antibodies to different CDKs. As expected, p27 was found to co-precipitate with CDK4 and CDK6 in exponentially growing NP-9 cells. Ectopic expression of p16 abolished CDK6-p27 complexes and resulted in the formation of new complexes with CDK2 and CycE. Unexpectedly, but consistent with results shown in a

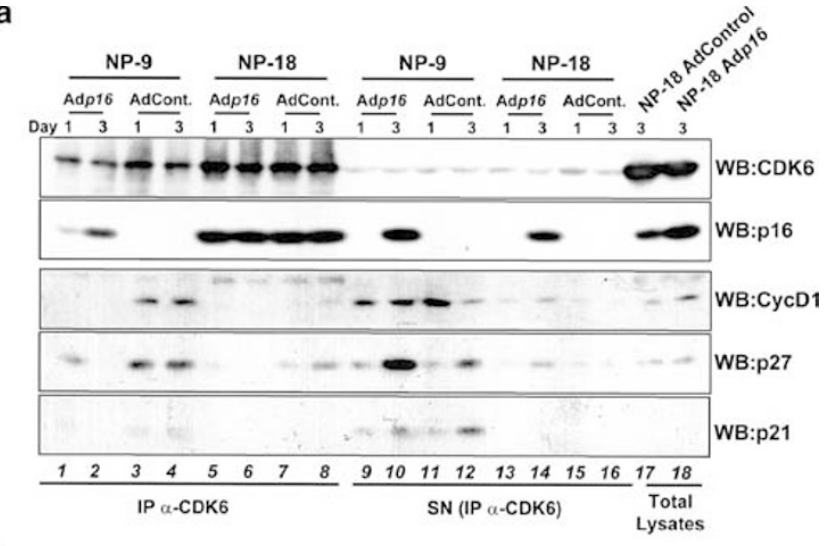

b
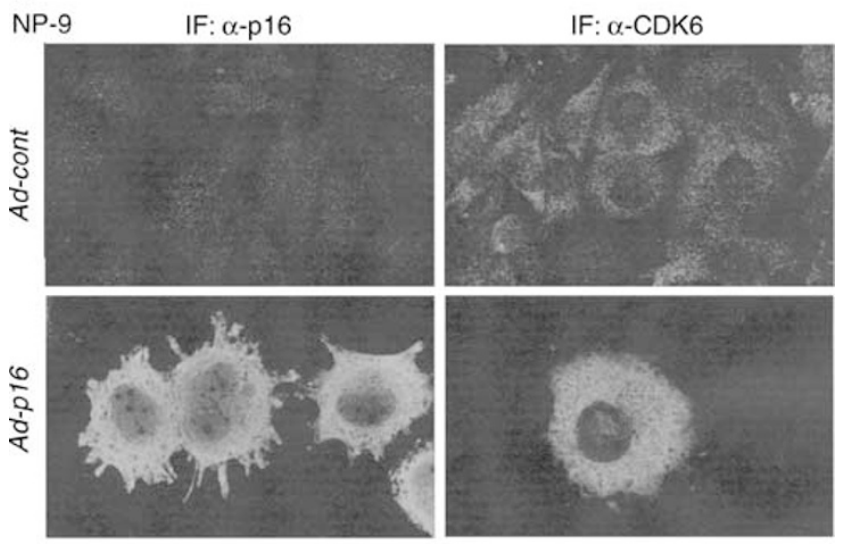

NP-18

IF: $\alpha-p 16$

IF: $\alpha-C D K 6$
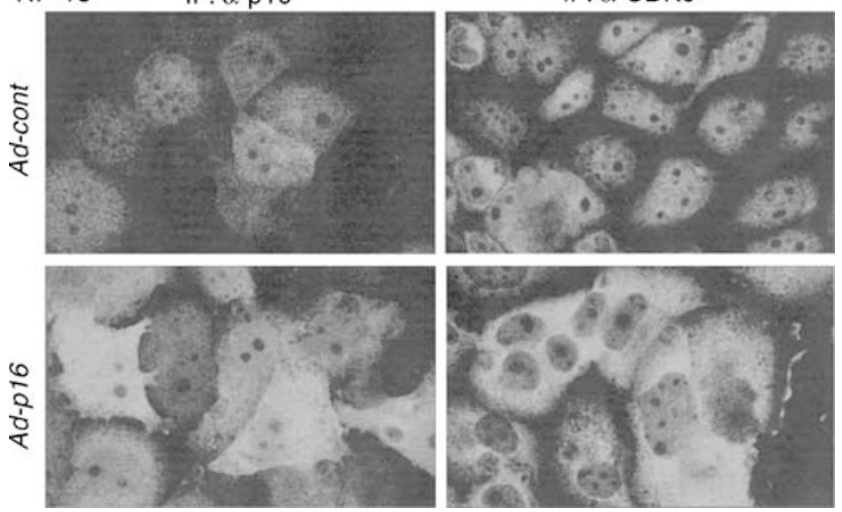

Figure 2 Effects of ectopic expression of p16 on CDK6 interaction with cyclin D1 and CKIs. (a) NP-9 and NP-18 cells were seeded at low density and infected $24 \mathrm{~h}$ later with Ad-control or Ad-p16 at a MOI of 50, or mock infected. Cell lysates were obtained from cells harvested 1 and 3 days after infection. Protein extracts were subjected to immunoprecipitation with CDK6-specific antibodies. Immunocomplexes were resolved in 12\% SDS-PAGE and Western blot analyzed with the indicated antibodies. Lanes 1-8: immunocomplexes. Lanes 9-16: CDK6immunodepleted protein extracts. Lanes 17-18: total protein extracts. (b) Similarly, NP-9 and NP-18 cells were seeded on glass coverslides and were infected as in (a). At 2 days after infection, cells were rinsed with PBS and fixed. Coverslides were then subjected to immunofluorescence using CDK6- and p16specific primary antibodies and Alexa-conjugated secondary antibodies. Cells were visualized and microphotographed in an epifluorescence microscope $(\times 400)$

Figure 3, CDK4-p27 binding was not altered following p16 overexpression (Figure 4). On the other hand, NP-18 cells presented much less p27 protein (see Figure 1) and 
a
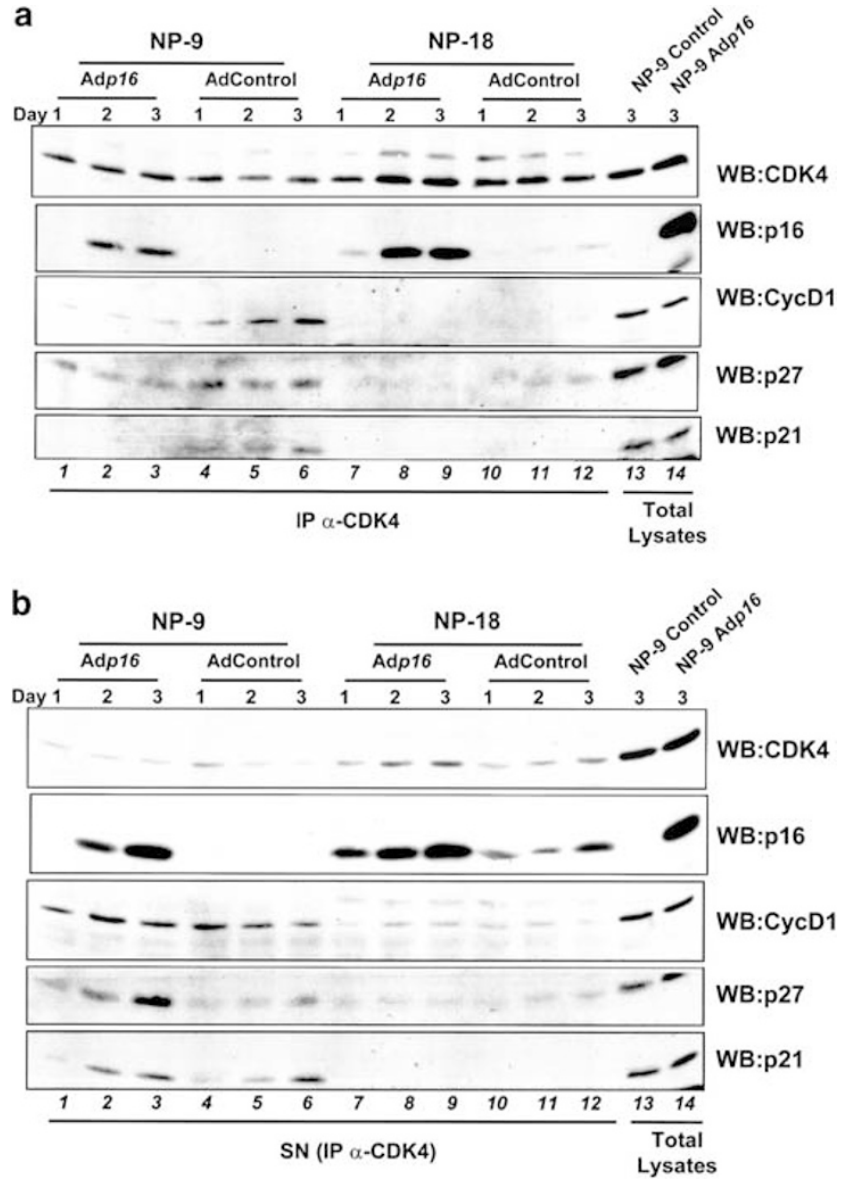

Figure 3 Effects of ectopic expression of p16 on CDK4 interaction with cyclin D1 and CKIs. NP-9 and NP-18 cells were seeded at low density and infected $24 \mathrm{~h}$ later with Ad-control or Ad-p16 at a MOI of 50, or mock infected. Cell lysates were obtained from cells harvested 1, 2 and 3 days after infection. Protein extracts were subjected to immunoprecipitation with CDK4-specific antibodies. Immunocomplexes were resolved in $12 \%$ SDS-PAGE and Western blot analyzed with the indicated antibodies. Lanes 1-12 (a): Immunocomplexes. Lanes 1-12 (b): CDK4-immunodepleted protein extracts. Lanes 13-14 (a and $\mathbf{b}$ ): Total protein extracts

p27-CDK4 and p27-CDK6 complexes than NP-9 cells. Ectopical expression of p16 in NP-18 cells did not result in significant changes in p27-containing complexes, although some CycE was bound to p27 3 days after p16 transduction. However, these new complexes contained only a minority of the CycE expressed in NP-18 cells (see Figure 1).

p21-CDK4 and p21-CDK6 complexes were detected in exponentially growing NP-9 cells, and this interaction was abrogated by day 3 following $\mathrm{p} 16$ expression. Only very low levels of CDK2 and CycE were co-immunoprecipitated with p21 in p16-expressing, but not in mock-infected NP-9 cells. In NP-18 cells no expression of p21 was detected.

\section{Coordinated inhibition of G1-CDK activities by $\mathrm{p} 16$}

After having demonstrated reorganization of G1-CDK complexes following overexpression of $p 16$, we tested its effects on G1-CDK activities. The kinase activities associated with CDK2, CycA and CycE were determined by immunocomplex a

IP $\alpha-\mathrm{p} 27$

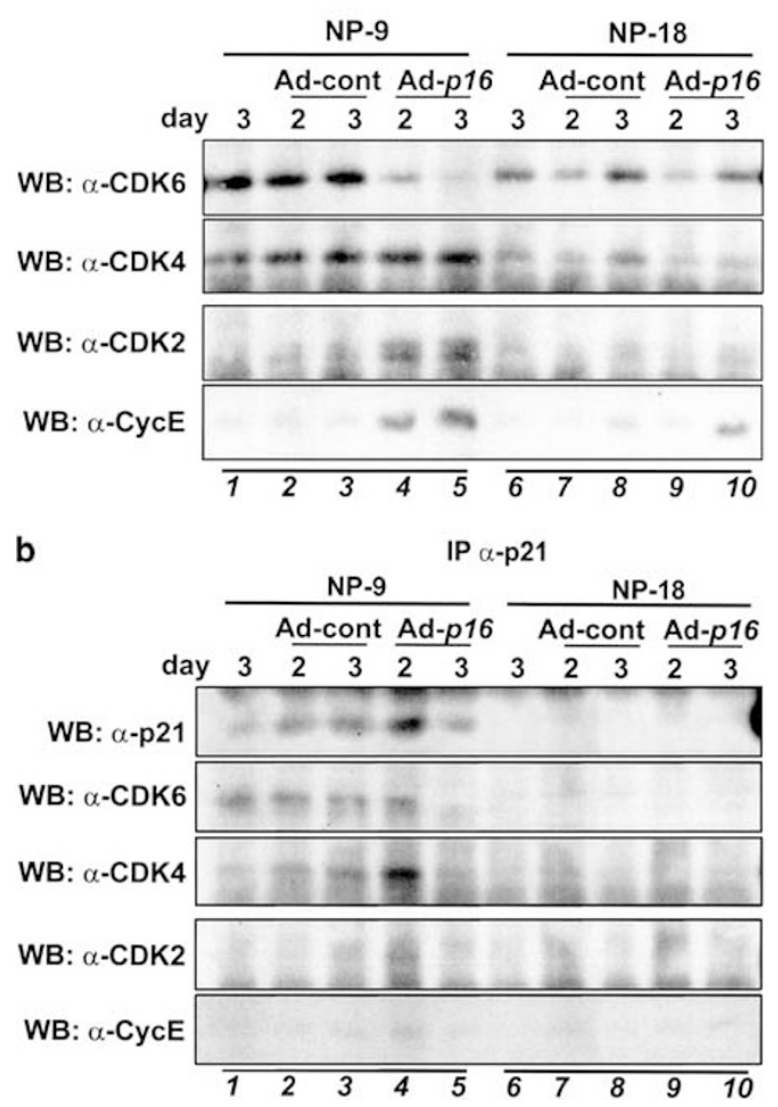

Figure 4 Ectopic expression of p16 induces redistribution of p27 and p21. The same protein extracts used in Figures 2 and 3 were immunoprecipitated with specific antibodies against p27 (a) or p21 (b). Immunocomplexes were resolved in $12 \%$ SDS-PAGE and analyzed by Western blot with the indicated antibodies

kinase assays using histone $\mathrm{H} 1$ as an exogenous substrate. As expected from the above results, overexpression of p16 in NP-9 cells triggered complete inhibition of CDK2- and CycAassociated activities. We also detected low CycE-associated activity, which was also slightly reduced (Figure 5 a, compare lanes 4-5 with lanes 1-3). In contrast, CDK2-associated activities in NP-18 cells were higher than in NP-9 cells and only slightly altered following overexpression of p16 (Figure 5a, lanes 6-10). Taken together, these results indicate that, in NP-9, p16 expression resulted in the abrogation of CDK6/4-p27/p21-CycD active complexes and inhibition of CDK2-CycE/CycA complexes, at least in part by redistribution of $p 27 / p 21$. Downregulation of CycA and CDK2 expression following $\mathrm{p} 16$ transduction also contributed to the downregulation of CDK2- and CycA-associated activities. Time-course experiments following ectopic expression of $\mathrm{p} 16$ in NP-9 cells showed that association of p21/p27 to CDK2 complexes and inhibition of CDK2 activity preceded downregulation of CycA-CDK2 complexes (Figures 1 and 5).

CycD-associated activities were difficult to detect in these cells in vitro. As an alternative, we measured changes in the phosphorylation of $\mathrm{pRB}$ in vivo with anti-pRB-phosphospecific antibodies. We analyzed the phosphorylation of the CDK4/6 preferred residue $\mathrm{S780}$ of pRB using a specific antibody 
against the phosphorylated antigen. As shown in Figure 6a, (lower panel) ectopic p16 expression inhibited S780-pRB phosphorylation in NP-9 and NP-18 cell lines, although this inhibition was more marked in NP-9 cells.
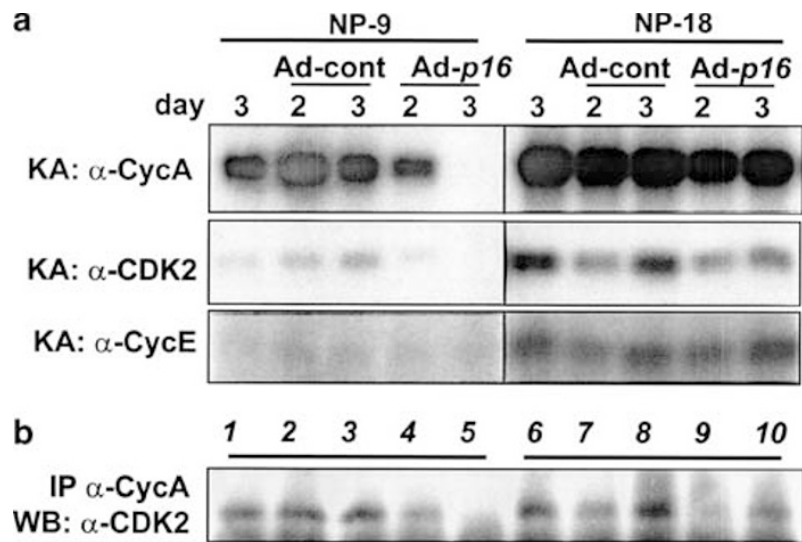

Figure 5 CDK2 kinase activity is inhibited by ectopic expression of $\mathrm{p} 16$. Protein extracts obtained as in Figures 2-4 were subjected to immunoprecipitation with specific antibodies $\alpha$-CycA, $\alpha$-CDK2 and $\alpha$-CycE. (a) Immunocomplexassociated kinase activity was determined using histone $\mathrm{H} 1$ as an exogenous substrate and ${ }^{32}$ P]ATP. Reaction mixture was resolved in $10 \%$ SDS-PAGE gels and histone $\mathrm{H} 1$-associated radioactivity was detected by autoradiography. (b) $\alpha$ CycA immunocomplexes were resolved in 10\% SDS-PAGE gels and analyzed by Western blot for the presence of CDK2

\section{Pocket protein phosphorylation}

In addition to site-specific phosphorylation of pRB, we tested the overall phosphorylation of the three pocket proteins. To this end, protein extracts were resolved in $6 \%$ polyacrylamideSDS gels, blotted and analyzed using specific antibodies. As reported earlier, hypo- and hyperphosphorylated forms of each protein can be distinguished by their differential mobility (reviewed in Graña et $a^{\beta 1}$ ). In both NP-9 and NP-18 exponentially growing cells (Figure 6a, lanes 1-3 and 6-8, respectively), pocket proteins were primarily hyperphosphorylated (p130 form 3, hyper-P p107 and hyper-P pRB). Ectopic expression of $\mathrm{p} 16$ led to a general reduction in pocket protein phosphorylation in both cell lines. However, the effects of $p 16$ expression in either cell line were different. The expression of p16 in NP-9 cells induced a phosphorylation pattern typical of quiescent cells, that is, forms 1 and 2 of $p 130$, hypo-P pRB and low expression of $p 107$. Instead, overexpression of $p 16$ in NP-18 cells resulted in the accumulation of hypophosphorylated p107 without reducing p107 levels. pRB appeared at least partially hyperphosphorylated, and p130 presented a slightly different pattern than that from NP-9 cells, consisting primarily of a form with mobility similar to form 2 (form 2-like). As p16-transduced NP-18 cells retained CDK2 kinase activity but not CDK4/6 activity, we hypothesized that this phosphoform of p130 could correspond to the 'form 2b' described earlier in cells lacking CycD activity. ${ }^{27,32,33}$ This form of p130 runs slightly slower than form 2 and does not associate with E2F-4 (see below). a

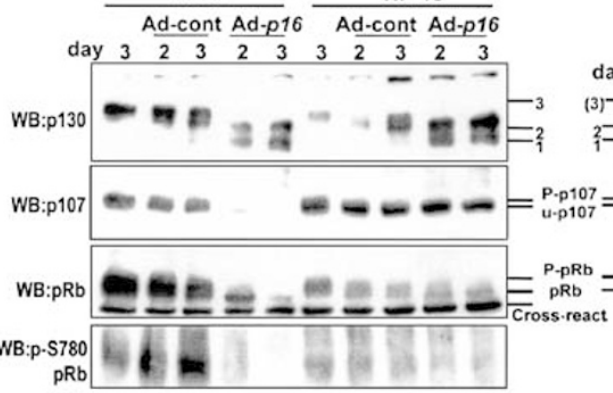

ct

$\$ 780$ b

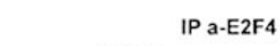
$\begin{array}{lllllllllllll}\text { day } & 3 & 2 & 3 & 2 & 3 & 3 & 2 & 3 & 2 & 3\end{array}$
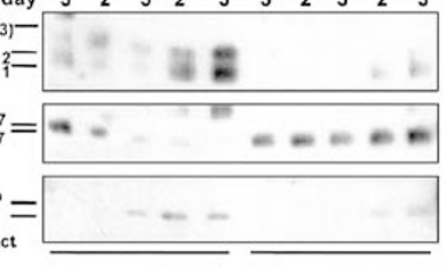

C day $\begin{array}{llllllllll}3 & 2 & 3 & 2 & 3 & 3 & 2 & 3 & 2 & 3\end{array}$

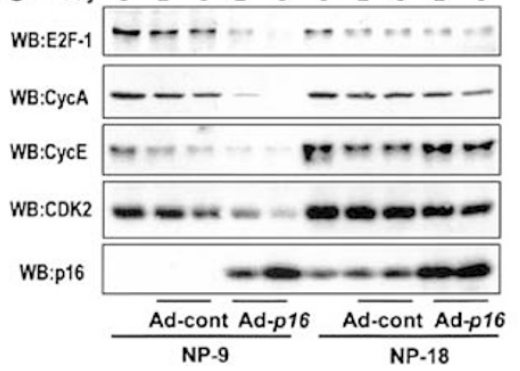

Figure 6 Ectopic expression of p16 induces changes in pocket protein phosphorylation, E2F-4 complex formation and in the expression of E2F-dependent genes. (a) Protein extracts used in Figures 2 and 3 were resolved in $6 \%$ SDS-PAGE gels in order to clearly separate different phosphorylation forms of each pocket protein, and were analyzed by Western blot using antibodies against p130, p107, pRb and pRb (phosphoserine 780), preferentially phosphorylated by cyclin D/CDK4-6 complexes. Different p130 phosphorylation forms are indicated as described previously (see text for references). p107-P and pRB-P indicate hyperphosphorylated p107 and pRb, respectively. (b) The same lysates were immunoprecipitated using $\alpha$-E2F-4 antibodies, and immunocomplexes were analyzed by Western blot as in (a). To note, only p130 forms 1 and 2 and hypophosphorylated pRb and p107 co-precipitate with E2F-4. (c) The same protein extracts were resolved in 12 and 15\% SDS-PAGE and analyzed by Western blot using specific antibodies against several E2F transcriptional targets and against p16, as indicated 


\section{Changes in E2F/pocket protein complexes and E2F-dependent transcription}

We next determined whether the observed changes in pocket protein phosphorylation were associated with changes in pocket protein-E2F complexes typical of growth-arrested cells (reviewed in Graña et $a^{\beta 1}{ }^{1}$ ). To this end, we performed E2F-4 immunoprecipitation and tested immunocomplexes for the presence of each pocket protein. In both NP-9 and NP-18 exponentially growing cells, the p107/E2F-4 complex was clearly detectable. Ectopic expression of p16, but neither Ad-control nor mock infection, led to disappearance of the p107/E2F-4 complexes and formation of E2F-4 complexes with hypophosphorylated p130 and pRB in NP-9 cells. In contrast, expression of p16 in NP-18 cells led to the formation of only a small amount of p130/E2F-4 and $\mathrm{pRB} / \mathrm{E} 2 \mathrm{~F}-4$ complexes. Interestingly, no 'form 2 like' co-immunoprecipitated with E2F-4 in NP-18 cells overexpressing p16, strongly suggesting that this was an inactive, partially phosphorylated form of p130, corresponding to 'form 2b' (see below). Finally, we determined whether the changes in pocket protein-E2F complexes were associated with changes in the expression of E2F-dependent genes. To this end, expression of several E2F-dependent gene products was analyzed by Western blot (Figure 6d). Consistent with the changes described above, expression of p16 in NP-9 cells led to the downregulation of E2F-1, p107, CycA and CycE. In contrast, expression of these E2Fdependent genes was not altered as a result of overexpressing p16 in NP-18 cells.

\section{Effects of chemical inhibition of CDK4 in NP-9 and NP-18 cells}

The results presented above suggest that p16-induced cell cycle arrest depends on coordinated inhibition of G1-CDK activities, complete hypophosphorylation of pocket proteins, formation of p130/E2F-4 and pRB/E2F-4 complexes and repression of E2F-target genes. To further demonstrate that inhibition of CycD-CDK activity is not sufficient to induce all these changes in the absence of CDK2 inhibition, we determined the effects of a small chemical inhibitor specific for CDK4(6)-CycD1, fascaplysine. ${ }^{24}$ This molecule appears to interfere with CycD-CDK activity without causing CKI redistribution. Thus, we anticipated that in the presence of fascaplysine CDK2associated activity would remain unaltered, mimicking p16 actions on NP-18 cells. First, we studied fascaplysine effects on pocket protein phosphorylation (Figure 7a). Following fascaplysine treatment, both NP-9 and NP-18 cell lines showed changes in pocket protein phosphorylation. Fascaplysine induced rapid changes in NP-18 cells. These included: p130 appeared in a partially phosphorylated form that comigrated with p130 from 293 cell extracts (described as 'form $2 b^{, 27,34}$ ); pRB seemed to accumulate in two discrete forms, one comigrating with hypophosphorylated pRB from p16-transduced NP-9 cells extract and the other showing partial phosphorylation; p107 showed clear hypophosphorylation but no change in protein levels. In

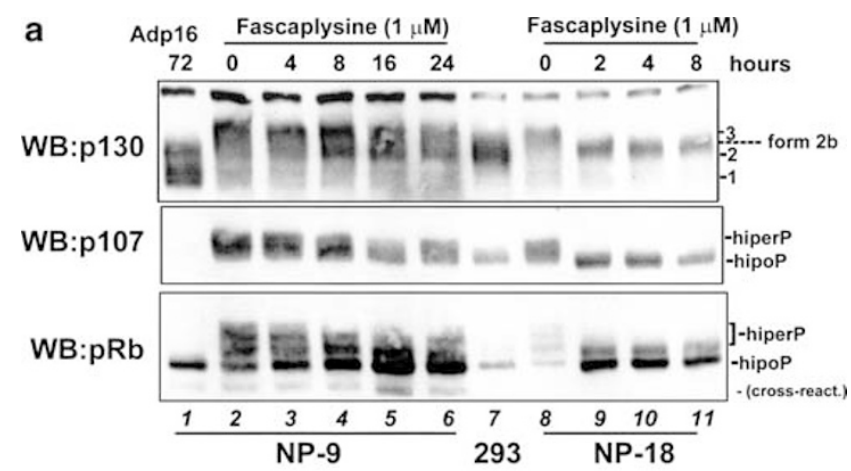

b
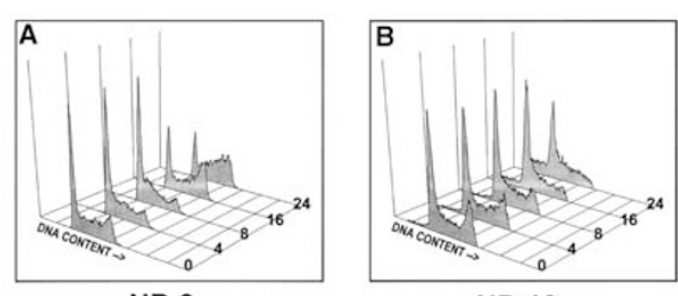

NP-18

Figure 7 Effects of the CKI fascaplysine on pocket protein phosphorylation and cell cycle progression. Exponentially growing NP-9 and NP-18 cells were treated with the CKI fascaplysine $(1 \mu \mathrm{M})$ and, at time-points indicated $(0,2,4,8,16$ and $24 \mathrm{~h})$, cells were collected and processed for Western blot analysis and DNA content determination by flow cytometry. (a) Immunoblot of p130, p107 and pRb. Cell lysates were loaded on 6\% SDS-PAGE gels to clearly resolve different phosphorylation forms of each pocket protein. Owing to high rates of cell death, it was not possible to obtain enough NP-18 protein extract after $8 \mathrm{~h}$ of treatment. Ad-p16-infected NP-9 cells $(72 \mathrm{~h})$ were run in parallel to aid recognition of phosphorylation forms from quiescent cells (lane 1); similarly, 293 cell lysate was run in order to identify phosphorylation forms present in cells lacking CDK4/6 activity but retaining CDK2 activity (i.e. p130 2b) (lane 7). Different p130 phosphorylation forms are indicated as described previously (see text for references). (b) Cell cycle profiles. Cells were collected and ethanol fixed. DNA content was determined by $\mathrm{PI}$ staining and flow-cytometry analysis

NP-9-treated cells, these changes were less rapid and less potent, but at $16 \mathrm{~h}$ after fascaplysine treatment $\mathrm{p} 130$ and $\mathrm{pRB}$ appeared partially phosphorylated, and p107 showed clear hypophosphorylation. In addition to p107, the expression of other E2F-target genes such asCycA or E2F-1 was analyzed and no changes were detected (data not shown). To study the effects of fascaplysine on cell cycle progression, exponentially growing cells were treated and collected at time points indicated, ethanol fixed and stained with PI. DNA content was quantified by flow-cytometry analysis. As shown in Figure $7 \mathrm{~b}$, fascaplysine did not induce $\mathrm{G} 1$ cell cycle arrest. However, we observed apoptosis in NP-18 cells following fascaplysine treatment.

\section{p21 ectopic expression protects NP-18 cells from p16-induced apoptosis}

p16 overexpression in NP-18 cells fails to block cell cycle progression and leads to apoptosis. Our data show that an imbalance in the relative levels of expression of CycE and p21/p27 proteins in this cell line determines escape from $\mathrm{p} 16$-induced cell cycle arrest. We have also observed that inhibition of D-type cyclin-CDK activity in NP-18 cells by 16 or fascaplysine results in apoptosis. Thus, if lack of 

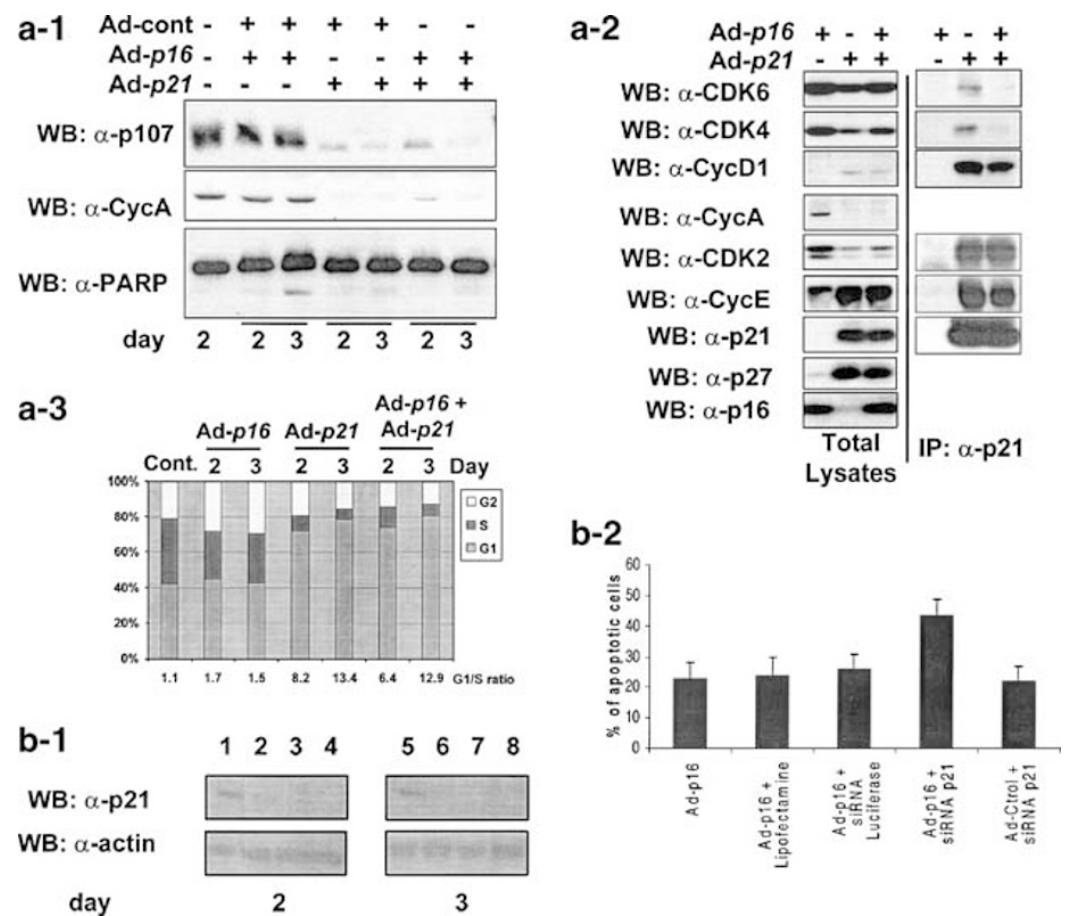

Figure 8 (a) Restitution of p21 ${ }^{\text {Cip } 1}$ protects NP-18 cells from p16-induced apoptosis. Exponentially growing NP-18 cells were infected with the indicated adenoviruses at a total $\mathrm{MOI}$ of $50 \mathrm{PFU} / \mathrm{cell}$. At 48 and $72 \mathrm{~h}$ after infection, cells were collected and processed for Western blot analysis and immunoprecipitation, or for DNA content determination by flow cytometry. (1) p107, CycA and PARP immunoblot. Cell lysates were resolved by SDS-PAGE in order to determine E2F-dependent protein expression (p107 and CycA) and apoptosis-associated PARP cleavage. (2) Interactions between p21 and G1-cyclin-CDK complexes. The same protein extracts used in (a) (day 2) were immunoprecipitated with specific $\alpha$-p21 antibodies, and the presence of several cyclins and CDKs in the immunocomplexes (right column) and in the total extracts (left column) was tested by Western blot analysis. To note, p21 binding to CDK4, CDK6, CDK2 and CycE and disruption of p21-CDK4 and p21-CDK6 binding were detected when p16 was coexpressed. (3) Cell cycle profiles. Cells were collected and ethanol fixed. DNA content was determined by PI staining and flowcytometry analysis. Light gray bars represent the percentage of cells in G0-G1 phase; dark gray bars represent S-phase cell \% and white bars represent G2-phase cell $\%$. The G1/S ratio is also shown. (b) Silencing of p21 expression by siRNA sensitizes NP-9 cells to p16-induced apoptosis. (1) p21 immunoblot. Exponentially growing NP-9 cells were transfected with increasing dose of siRNAp21 (lanes 1 and 5: control samples; lanes 2 and 6: $0.1 \mu \mathrm{g}$; lanes 3 and 7: $0.2 \mu \mathrm{g}$; lanes 4 and 8: $0.4 \mu \mathrm{g}$ ) and collected 48 and $72 \mathrm{~h}$ later for Western blot analysis. (2) Apoptosis quantification by Annexin-V binding. Afterwards, they were infected with the indicated adenoviruses at a total $\mathrm{MOI}$ of 50 . At $72 \mathrm{~h}$ after infection, cells were collected and processed for Annexin-V binding and flow-cytometry analysis

p21/p27 binding to CDK2 complexes prevents p16 from inducing $\mathrm{G} 1$ arrest, restitution of p21 and/or p27 activity would result in cell cycle arrest and rescue from apoptosis. To test this hypothesis, NP-18 cells were transduced with Ad-p21 ${ }^{\text {Cip } 1}$ or in combination with Ad-p16. Overexpression of p21 or p21 and p16, but not p16 alone, led to G1 arrest (Figure 8a-3). The G1/S ratio shifted from 1.5 in control and p16-expressing cells to 13 in p21- and p16/p21-expressing NP-18 cells 3 days after adenovirus infection (Figure 8a-3). Accordingly, ectopic expression of p21 led to the downregulation of p107 and CycA (Figure 8a-1, upper and mid panel). Interestingly, p21 protected cells from p16-induced apoptosis, as observed by PARP cleavage analysis (Figure 8a-1, lower panel). Finally, our data also show that when p21 is overexpressed, it efficiently binds CycE/CDK2 and CycD1/CDK4 complexes. Most importantly, ectopic expression of $\mathrm{p} 16$ disrupts p21 interaction with CDK4 and CDK6 even when p21 is expressed at high levels (Figure 8a-2). All these data taken together indicate that the G1 control machinery in NP-18 cells responds to redistribution of p21/p27 in response to p16 overexpression, but fails to do so as the endogenous levels of p21/p27 in NP-18 cells are insufficient to inactivate the high levels of CycE/A-CDK2 activity in these cells.

\section{Silencing of p21 expression by siRNA sensitizes NP-9 cells to p16-induced apoptosis}

Since our results suggest that low p21 expression in NP-18 cells is responsible for p16-induced apoptosis, we asked whether silencing of $\mathrm{p} 21$ expression in NP-9 cells would result in increased apoptosis after ectopic expression of p16. First, we checked the efficiency of p21 expression silencing by treating NP-9 cells with increasing dose of siRNA (Figure 8b1). After that, cells were transfected with $0.4 \mu \mathrm{g} / \mathrm{ml}$ of siRNAp21 or an irrelevant siRNA and were subsequently infected with Ad-p16. Cell cycle profiles showed that ectopic expression of $\mathrm{p} 16$ resulted in a drastic reduction of the percentage of cells in $S$ phase, while attenuation of p21 expression completely abrogated this effect (data not shown). Finally, we have quantified the level of apoptosis induction by Annexin- $\mathrm{V}$ binding and cytometric analysis (Figure 8b-2). Although some toxicity was observed in Lipofectaminetreated cells as well as in irrelevant siRNA-transfected cells, attenuation of p21 expression resulted in a significant increase in the percentage of apoptotic cells after Ad-p16 infection. Importantly, p21 silencing did neither induce apoptosis nor predisposed cells to toxicity by Ad-control infection. 


\section{Discussion}

When p16 is overexpressed in pancreatic cell lines grown in culture and in mice as subcutaneous xenografts, it inhibits proliferation and tumor growth by different mechanisms. We have previously shown that p16 overexpression induces growth arrest in NP-9 cells and apoptosis in NP-18. In this report, we have studied in detail the mechanisms by which p16 mediates these two distinct responses in pancreatic tumor cells. Overexpression of p16 caused coordinated inhibition of G1-CDK activities in NP-9 but not in NP-18 cells. p16 induced inhibition of G1-CDK activities by: (1) binding to CDK4/6 and disrupting CycD-CDK4/6 active complexes; (2) release and redistribution of p21/p27 proteins to inhibit CycE/ A-CDK2 complexes; and (3) changes in the expression of regulatory proteins (CycA, CDK2, p27) that modulate CDK2 activity. These results are in agreement with those observed in U2-OS cells expressing an inducible p16 transgene. ${ }^{35}$ In addition to p21/p27 reassortment, p16 induces p27 accumulation. Since CDK-mediated phosphorylation of p27-Thr187 leads to proteasome-dependent degradation, coordinated inhibition of G1-CDK activities by 16 expression might be responsible for p27 stabilization and accumulation. ${ }^{36}$ As expected, inactivation of G1-CDK activities led to hypophosphorylation of pocket proteins, formation of p130/E2F-4 and pRB/E2F-4 complexes, E2F transcriptional repression and subsequent $\mathrm{G} 1$ cell cycle arrest.

In contrast, ectopic expression of p16 in NP-18 cells did not inhibit cell cycle progression. Our data showed a predominant p16-CDK6 complex and reduced binding of CycD1 and p21/ p27 proteins to CDK4 and CDK6 in nontransduced NP-18 cells, correlating with low but detectable CDK4/6 activities found in other studies (O Bachs, personal communication). Indeed, the low levels of p21/p27 expression in these cells may preclude the formation of active trimeric D-type cyclinCDK-Cip/kip active complexes. ${ }^{37}$

Inhibition of CDK4/6 activities by ectopically expressed $\mathrm{p} 16$ protein led to partial phosphorylation of the three pocket proteins, since CDK2 continued to be active in these cells. The partial hyperphosphorylation of $\mathrm{p} 130$ and $\mathrm{pRB}$ was sufficient to prevent the formation of $\mathrm{p} 130 / \mathrm{E} 2 \mathrm{~F}-4$ and $\mathrm{pRB} / \mathrm{E} 2 \mathrm{~F}-4$ complexes following $\mathrm{p} 16$ overexpression. Consequently, we observed neither repression of E2F-dependent genes nor growth arrest. Intriguingly, accumulation of hypophosphorylated p107 and p107/E2F-4 complexes in these conditions did not result in cell cycle arrest, consistent with the previous data. ${ }^{14}$ In agreement with these results, inhibition of CDK4 with fascaplysine in both NP-9 and NP-18 also led to partial inhibition of pocket protein phosphorylation but failed to induce growth arrest. Thus, chemical inhibition of CDK4 or inhibition of CDK4/6 by $\mathrm{p} 16$ in the absence of CDK2 inhibition is not sufficient to induce growth arrest. As expression of p16 failed to inhibit CDK2 activity, we hypothesized that the relative levels of $\mathrm{p} 21 / \mathrm{p} 27$ with respect to CycE levels in NP-18 cells are insufficient to downregulate CDK2 activity by $\mathrm{p} 16$ mediated reassortment of endogenous p21/p27. Alternatively, it was conceivable that the CDK2 complexes expressed in NP-18 cells were resistant to p21/p27 in NP-18 cells. Reconstitution of p21 in NP-18 cells shows that, given sufficient levels of p21, CDK2 is efficiently inhibited and NP-
18 cells arrest in $\mathrm{G} 1$. In addition, ectopic expression of both p16 and p21 clearly shows that p16 can disrupt CDK4-p21 complexes even when p21 is overexpressed.

The formerly accepted predominance of CDK2 in the control of G1-S progression has been recently challenged. First, it has been shown that CDK2 activity is dispensable for the growth of different colon carcinoma cell lines, among other tumor cell lines. ${ }^{38}$ After that, targeted disruption of CDK2 gene in mice has shown that CDK2 is also dispensable for embryonic development and cell cycle progression, as knocked out mice were fully viable. ${ }^{39}$ Reinforcing this idea, CycE1 and CycE2 double knockout mice are also viable and show no major developmental problems. ${ }^{40,41}$ However, minor cell cycle aberrations observed in cultured embryonic fibroblasts from these mice (CDK2KO, CycE1/E2DKO) seem to indicate an increased sensitivity to antiproliferative signaling during G1 phase, as they enter senescence earlier and show increased resistance to oncogene-induced transformation. Results presented here demonstrate that cell cycle arrest following 16 overexpression depends on the relative levels of cyclin/CDK2 complexes and p21/p27, suggesting a prevalence of CDK2 activity in the control of cell cycle progression. However, our data are not in contradiction to these recent findings, as it pinpoints to the sufficiency of CDK2 to override a p16-induced cell cycle arrest, independent of the need that growing normal or tumor cells may have on CDK2 activity.

Interestingly, a number of observations made in this study suggested differences between the affinities of CDK4 and CDK6 kinases for CKIs. For instance, endogenous p16 protein bound exclusively to CDK6 in NP-18 cells, and no p16-CDK4 complexes were found in nontreated cells. Moreover, ectopic expression of p16 in NP-9 cells efficiently disrupted CDK6-p27 complexes, while CDK4-p27 complexes were less affected. These differences seem to indicate that, although CDK4 and CDK6 are structurally related and activated by the same subset of G1 cyclins, CKIs might regulate them differentially. If this is the case, fluctuations of CKIs in response to cellular insults might have different consequences depending on the relative expression of CDK4 and CDK6 in a particular cell type. Further studies will be needed to test these possibilities.

One intriguing aspect of this study is the finding that $\mathrm{p} 16$ induces apoptosis in NP-18. Although p16 does not induce cell cycle arrest, it has strong antiproliferative effects as a consequence of apoptosis induction in NP-18 cells. Other groups using similar approaches in different cells have also detected p16-induced cell death ${ }^{17-21}$, reviewed in Calbó and Mazo $^{16}$ ), but the molecular mechanisms remain unclear. It has been proposed that p16 expression results in p53dependent apoptosis, ${ }^{17,18}$ but lack of wt-p53 gene in NP-18 cells makes this unlikely. It has also been described that $\mathrm{p} 16$ induces downregulation of $\mathrm{Bcl}-2,{ }^{17}$ but we did not detect changes in $\mathrm{Bcl}-2$ or Bax expression following p16 expression in NP-18 cells (data not shown). We considered the possibility that p16-induced apoptosis in NP-18 cells was a default response triggered by $\mathrm{p} 16$ in the absence of CDK2 inhibition and growth arrest. If so, reconstitution of the defective pathway that prevents CDK2 inhibition and growth arrest should also prevent apoptosis. Our data support this 
hypothesis since ectopic expression of p21 prevents p16induced apoptosis and induces growth arrest. Similarly, silencing of p21 expression in NP-9 cells by means of small interference RNA was sufficient to override a p16-induced cell cycle arrest, resulting in a concomitant induction of apoptosis. A growing body of evidence indicates that control of p21 expression and regulation of its subcellular localization play a central role in cell fate determination in response to several antiproliferative signals. $^{42}$ If so, p16 upregulation would initiate cell cycle arrest and apoptosis signals as p53 activation does, and in both cases p21 function would decide the fate of cells. However, we cannot discern whether p21 suppression of p16-induced apoptosis is the result of a direct antiapoptotic function of p21 or whether suppression of apoptosis is dependent on inhibition of CDK2. Since p21 protein can interfere with proapoptotic pathways at different levels, ${ }^{43}$ further investigation is needed to elucidate specific mediators of $\mathrm{p} 16$-induced apoptosis.

It is also important to determine whether CDK4/6 and CDK2 play opposite roles in the regulation of apoptosis. Our data suggest a protective antiapoptotic role mediated by CDK4/ CDK6, since inhibition of CDK4/6 in the presence of high CDK2 activity makes cell enter an apoptotic pathway. While unknown CDK2 substrates could also participate into apoptosis induction, it is likely that differential phosphorylation of pocket proteins and specific E2F-dependent transcription regulation links uncoordinated G1-CDK activities to cell death. This notion is supported by the findings of Dick and Dyson, ${ }^{44}$ who demonstrate the ability of $p R b$ to control separately E2F1-dependent cell cycle progression and apoptosis by using differentially regulated and physically separated protein domains.

Lack of broad-spectrum efficient therapies for cancer has motivated strong efforts to develop specific approaches based on targeting molecular features of cancer cells. Restoration of lost tumor-suppressor functions has arisen as one promising strategy, given the high-frequency mutation of

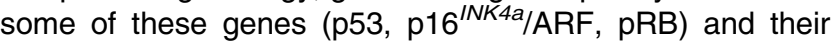
specific actions on tumor cells. However, preclinical experiments have shown that the pattern of genetic alterations might determine the success or the failure of such strategies. Overexpression of $\mathrm{CycE}$, together with p27 downregulation, has been related to tumor progression and stage in a number of malignancies like breast, stomach and colorectal cancer, and osteosarcoma (summarized in Donnellan and Chetty ${ }^{45}$ ). Moreover, its prognostic value has been described in some of these cases. On the other hand, cytosolic localization of p21 is related to poor prognosis in breast cancer ${ }^{46}$ and high expression of this protein may be responsible for resistance to chemotherapy in a number of models (reviewed in Weiss ${ }^{42}$ ). Characterizing the relationship between the genotype of cancer cells and their sensitivity to different molecular therapies is relevant and important in order to provide useful tools for tailoring specific therapies to individual tumor types. In the present study, we have provided insight into the cellular pathways that determine different responses to $\mathrm{p} 16^{I N K 4 a}$ gene transfer. The overall results suggest that sensitivity to $\mathrm{G} 1$ intervention such as restoration of tumor-suppressor functions depend on whether CDK2 activity is overexpressed.

\section{Materials and Methods}

\section{Cell culture conditions}

NP-9 and NP-18 cell lines were derived from human pancreatic adenocarcinomas, which had been perpetuated as xenografts in nude mice. ${ }^{23}$ NP-9 cells were maintained in Dulbecco's modified Eagle's medium and F12 mixture (1:1), and NP-18 cells were maintained in RPMI-1640 (Cellgro, Herndon, VA, USA), both supplemented with $10 \%$ fetal bovine serum (FBS) (Sigma, St. Louis, MO, USA) at $37^{\circ} \mathrm{C}$ in a humidified atmosphere with $5 \% \mathrm{CO}_{2}$. The status of several genes and their expression is summarized in Table 1.

Fascaplysine was kindly provided by Novartis, and used to inhibit specifically CDK4 activity at $1 \mu \mathrm{M} .{ }^{24} \mathrm{~A} 10 \mathrm{mM}$ stock solution was prepared in DMSO.

\section{Antibodies}

Anti-p107 (sc-318), anti-p130 (sc-317), anti-pSer780pRb (sc-12901), antip21 (sc-397), anti-p27 (sc-528), anti-cyclin A (CycA) (sc-596), anti-Cdk2 (sc-163), anti-CDK4 (sc-601), anti-CDK6 (sc/C21) and anti-E2F-4 (sc-512) rabbit polyclonal antibodies; anti-cyclin D1 (sc-8396), anti-CycE (sc-247 and sc-248), anti-pRb IF8 (sc-102) and anti-E2F-1 KH95 (sc-251) mouse monoclonal antibodies were obtained from Santa Cruz Biotechnology. Anti-p130 mAb (R27020) was from Transduction Laboratories (Lexington, KY, USA). Anti-p16 mAb (G175-405) and anti-PARP mAb (556493) were from Pharmingen (San Diego, CA, USA). Anti-pRb was a mix of monoclonal antibodies (XZ35, XZ56, XZ61, XZ91, XZ105, XZ121, XZ133 and XZ145), kindly provided by $E$ Harlow.

For Western blot applications, horseradish peroxidase (HRP)conjugated secondary antibodies were used. Anti-mouse-HRP (NA931) and anti-rabbit-HRP (SJ434) were obtained from Amersham and used at $1 / 10000$ dilution. For immunofluorescence, Alexa448-conjugated antimouse (A11058) and anti-rabbit (A11008) were purchased from Molecular Probes (Eugene, OR, USA).

\section{Adenovirus production and infection}

All the recombinant adenoviruses used were replication-defective type- 5 adenoviruses. Adenoviruses containing full-length $p 16^{\text {INK4a }}$ CDNA under the control of a Rous sarcoma virus promoter (Ad5RSV-p16, Ad-p16) were provided by J Fueyo. Adenoviruses encoding lacZ gene under the control of a cytomegalovirus (CMV) promoter or empty adenoviruses were used as controls. Adenoviruses encoding the $\mathrm{p} 21^{\mathrm{Cip} 1}$ gene under the control of a CMV promoter were provided by W El-Deiry. Viral stocks were amplified using 293 cells, which provide the adenovirus E1 region in trans. Viral titers were determined by plaque assay. ${ }^{25}$ Titers obtained ranged from $5 \times 10^{9}$ to $5 \times 10^{10} \mathrm{PFU} / \mathrm{ml}$. Infection conditions and optimal multiplicity of infection (MOI) were previously determined using adenovirus carrying the lacZ reporter gene and X-gal staining. ${ }^{26}$ Briefly, cells were seeded $24 \mathrm{~h}$ before adenovirus infection. The viral stocks were diluted to reach an $\mathrm{MOI}$ of 50 in serum-free medium, added to cell monolayer and incubated for $2 \mathrm{~h}$. Mock-infected cells were incubated with serum-free medium. After $2 \mathrm{~h}$ period, cells were refed with medium containing $10 \%$ FBS.

\section{Flow-cytometry analysis}

All measurements were performed on Facscan (BD, Mountain View, CA, USA) or EPICS-XL (Coulter, Villepinte, France). For DNA content 
quantification, cells were processed as described earlier. ${ }^{22}$ Data from 10000 cells were collected and analyzed using ModFitLT V2.0 software.

\section{Western blot analysis and immunoprecipitation}

Whole protein lysates were obtained essentially as described previously. ${ }^{27,28}$ Briefly, cells were lysed in buffer containing $50 \mathrm{mM}$ Tris- $\mathrm{Cl}(\mathrm{pH}$ 7.4), $5 \mathrm{mM}$ EDTA, $250 \mathrm{mM} \mathrm{NaCl}, 50 \mathrm{mM} \mathrm{NaF}, 0.1 \%$ Triton X-100, $0.1 \mathrm{mM}$ $\mathrm{Na}_{3} \mathrm{VO}_{4}, 2 \mathrm{mM}$ PMSF, $10 \mu \mathrm{g} / \mathrm{ml}$ leupeptin, $4 \mu \mathrm{g} / \mathrm{ml}$ aprotinin and $4 \mu \mathrm{g} / \mathrm{ml}$ pepstatin (lysis buffer). Immunoprecipitation and Western blots were performed as described previously. ${ }^{27,28}$ Briefly, protein extracts (250$500 \mu \mathrm{g}$ ) were incubated for $1 \mathrm{~h}$ at $4{ }^{\circ} \mathrm{C}$ with specific antibodies, and immunocomplexes were precipitated with $25 \mu \mathrm{l}$ protein A-Sepharose beads (Pierce, Rockford, IL, USA) for $2 \mathrm{~h}$ at $4^{\circ} \mathrm{C}$ and washed four times in lysis buffer. Complexes were eluted from beads by adding $1.5 \mathrm{Laemmli}$ sample buffer. Whole-cell lysates or immunocomplexes were resolved by SDS-PAGE and transferred onto PVDF membranes (Immobilon-P, Millipore, Billerica, Mass, USA) in $10 \mathrm{mM} \mathrm{CAPS} \mathrm{(pH} \mathrm{11)} \mathrm{containing} 10 \%$ methanol. Gels (10 and 12\%) were run to determine the expression of cyclins, CDKs, p16, p21, p27 and E2F proteins and 6 and $8 \%$ gels to determine the phosphorylation status of pocket proteins. The transferred membranes were probed with specific primary antibodies and the corresponding HRP-conjugated secondary antibody (Amersham, Little Chalfort, Buckinghamshire, UK). Bands were visualized by incubating the membranes with enhanced chemiluminescence reagent (NEN) and exposing the membranes to X-ray film.

\section{In vitro kinase assays}

CDK2 kinase activity was determined from CDK2, CycE and CycA immunopurified complexes as described previously. ${ }^{29,30}$ Complexes were immunoprecipitated with specific antibodies from whole protein extracts (40 $\mu \mathrm{g}$ for CDK2 and $200 \mu \mathrm{g}$ for CycE). Kinase assays were performed at

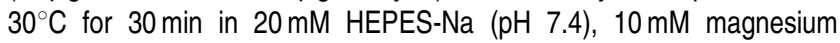

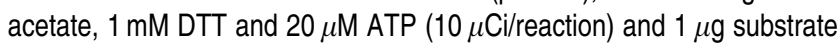
(Histone H1). Substrates were resolved in $12 \%$ SDS-PAGE, gels were dried and visualized by autoradiography.

\section{Annexin- $\mathrm{V}$ binding assays}

Apoptosis was assessed by Annexin-V-FITC staining (Genzyme Corp., Cambridge, MA, USA). Supernatant and platted cells were collected $72 \mathrm{~h}$ after infection, washed with phosphate-buffered saline (PBS) and resuspended in binding buffer. A total of $5 \times 10^{5}$ cells were collected, washed in PBS and resuspended in $0.5 \mathrm{ml}$ binding buffer containing a final concentration of $0.5 \mu \mathrm{g} / \mathrm{ml}$ Annexin-V-FITC and $5 \mu \mathrm{g} / \mathrm{ml}$ propidium iodide (PI). Cells were incubated at room temperature for $1 \mathrm{~h}$ in the dark. Annexin staining combined with $\mathrm{PI}$ exclusion allows determination of the percentage of early apoptotic cells. Duplicate dishes of each sample were analyzed with an ELITE flow cytometer. ELITE software was used for data analysis.

\section{Small interfering RNA (siRNA) treatment}

For suppression of cellular p21 expression, siRNA that specifically targets p21 mRNA was designed and synthesized according to the manufacturer's protocol (Silencer ${ }^{\mathrm{TM}}$ siRNA Construction Kit, Ambion Inc., Austin, TX, USA). The sense sequence was $5^{\prime}$-aacttcgacttgtcaccgag-3', corresponding to residues $148-168$ of the coding region of human p21 mRNA. NP-9 cells were seeded in six-well plaques. After $24 \mathrm{~h}$, they were transfected with anti-p21 siRNA or an irrelevant siRNA (firefly luciferase) during $16 \mathrm{~h}$, using a mixture $3: 4$ of Lipofectamine and Plus reagents (Invitrogen Life Technologies, Carlsbad, CA, USA), and infected during $4 \mathrm{~h}$ at a $\mathrm{MOI}$ of 50 of Ad-p16 or Ad-control after transfection.

\section{Acknowledgements}

We thank Juan Fueyo and Wafik El-Deiry for providing recombinant adenoviruses and Ed Harlow for antibodies. We thank Mayumi Kataoka and Jaume Comas for flow cytometric analysis and May Truongcao, Julita Yarwood and Deborah Pons for technical assistance. We thank Neus Carbó for carefully reading of the manuscript, and Robin Rycroft for editorial help. JC and CS were partially supported by fellowships from Dirección General de Investigación Científica y Técnica (Ministerio de Educación y Cultura, Spain). This work was supported in part by grants to AM including grants from the Ministerio de Ciencia y Tecnología (SAF-980042 and SAF2002-04122-C03-03) and from the Instituto de Salud Carlos III (G03-156) and to XG including a grant from the National Institute of General Medical Sciences (NIH-R29, GM54894), a grant (NIH R01, Al45450) and a Career Development Award (K02 Al01823) from the National Institute of Allergy and Infectious Diseases and a WW Smith grant (A9802/9901). Facilities used for this work were supported in part by a Shared Resources for Cancer Research Grant R24 (CA88261-01).

\section{References}

1. Ruas M and Peters G (1998) The p16INK4a/CDKN2A tumor suppressor, its relatives. Biochim. Biophys. Acta 1378: F115-F177

2. Kamb A, Shattuck-Eidens D, Eeles R, Liu Q, Gruis NA, Ding W, Hussey C, Tran T, Miki $Y$ and Weaver-Feldhaus $J$ et al. (1994) Analysis of the p16 gene (CDKN2) as a candidate for the chromosome $9 p$ melanoma susceptibility locus. Nat. Genet. 8: 23-26

3. Whelan AJ, Bartsch D and Goodfellow PJ (1995) Brief report: a familial syndrome of pancreatic cancer and melanoma with a mutation in the CDKN2 tumor-suppressor gene. N. Engl. J. Med. 333: 975-977

4. Sharpless NE, Bardeesy N, Lee KH, Carrasco D, Castrillon DH, Aguirre AJ, Wu EA, Horner JW and DePinho RA (2001) Loss of p16Ink4a with retention of p19Arf predisposes mice to tumorigenesis. Nature 413: 86-91

5. Krimpenfort P, Quon KC, Mooi WJ, Loonstra A and Berns A (2001) Loss of p16Ink4a confers susceptibility to metastatic melanoma in mice. Nature 413: 83-86

6. Lukas J, Parry D, Aagaard L, Mann DJ, Bartkova J, Strauss M, Peters G and Bartek J (1995) Retinoblastoma-protein-dependent cell-cycle inhibition by the tumour suppressor p16. Nature 375: 503-506

7. Medema RH, Herrera RE, Lam F and Weinberg RA (1995) Growth suppression by p16ink4 requires functional retinoblastoma protein. Proc. Natl. Acad. Sci. USA 92: 6289-6293

8. Serrano M, Hannon GJ and Beach D (1993) A new regulatory motif in cell-cycle control causing specific inhibition of cyclin D/CDK4. Nature 366: 704-707

9. Sherr CJ and Roberts JM (1999) CDK inhibitors: positive and negative regulators of G1-phase progression. Genes Dev. 13: 1501-1512

10. Bruce JL, Hurford Jr RK, Classon M, Koh J and Dyson N (2000) Requirements for cell cycle arrest by p16INK4a. Mol. Cell. 6: 737-742

11. van den Heuvel S and Harlow E (1993) Distinct roles for cyclin-dependent kinases in cell cycle control. Science 262: 2050-2054

12. Lukas J, Herzinger T, Hansen K, Moroni MC, Resnitzky D, Helin K, Reed SI and Bartek J (1997) Cyclin E-induced S phase without activation of the pRb/E2F pathway. Genes Dev. 11: 1479-1492

13. Alevizopoulos K, Vlach J, Hennecke S and Amati B (1997) Cyclin E and c-Myc promote cell proliferation in the presence of $\mathrm{p} 16 \mathrm{INK} 4 \mathrm{a}$ and of hypophosphorylated retinoblastoma family proteins. EMBO J. 16: 5322-5333

14. Calbó J, Parreno M, Sotillo E, Yong T, Mazo A, Garriga J and Grana X (2002) G1 cyclin/CDK coordinated phosphorylation of endogenous pocket proteins 
differentially regulates their interactions with E2F4 and E2F1 and gene expression. J. Biol. Chem. 27: 50263-50274

15. Connell-Crowley L, Elledge SJ and Harper JW (1998) G1 cyclin-dependent kinases are sufficient to initiate DNA synthesis in quiescent human fibroblasts. Curr. Biol. 8: 65-68

16. Calbó $J$ and Mazo A (2003) p16INK4a as a tumor suppressor with therapeutic applicability. Drugs Future 28: 153-166

17. Kataoka M, Wiehle S, Spitz F, Schumacher G, Roth JA and Cristiano RJ (2000) Down-regulation of bcl-2 is associated with p16INK4-mediated apoptosis in non-small cell lung cancer cells. Oncogene 19: 1589-1595

18. Katsuda K, Kataoka M, Uno F, Murakami T, Kondo T, Roth JA, Tanaka N and Fujiwara $\mathrm{T}$ (2002) Activation of caspase-3 and cleavage of $\mathrm{Rb}$ are associated with p16-mediated apoptosis in human non-small cell lung cancer cells. Oncogene 21: 2108-2113

19. Kim M, Katayose Y, Rojanala L, Shah S, Sgagias M, Jang L, Jung YJ, Lee SH, Hwang SG and Cowan KH (2000) Induction of apoptosis in p16INK4A mutant cell lines by adenovirus-mediated overexpression of p16INK4A protein. Cell Death Differ. 7: 706-711

20. Tamm I, Schumacher A, Karawajew L, Ruppert V, Arnold W, Nussler AK Neuhaus P, Dorken B and Wolff G (2002) Adenovirus-mediated gene transfer of P16INK4/CDKN2 into bax-negative colon cancer cells induces apoptosis and tumor regression in vivo. Cancer Gene Ther. 9: 641-650

21. Schreiber M, Muller WJ, Singh G and Graham FL (1999) Comparison of the effectiveness of adenovirus vectors expressing cyclin kinase inhibitors p16INK4A, p18INK4C, p19INK4D, p21(WAF1/CIP1) and p27KIP1 in inducing cell cycle arrest, apoptosis and inhibition of tumorigenicity. Oncogene 18: 1663-1676

22. Calbó J, Marotta M, Cascallo M, Roig JM, Gelpi JL, Fueyo J and Mazo A (2001) Adenovirus-mediated wt-p16 reintroduction induces cell cycle arrest or apoptosis in pancreatic cancer. Cancer Gene Ther. 8: 740-750

23. Villanueva A, Garcia C, Paules AB, Vicente M, Megias M, Reyes G, de Villalonga P, Agell N, Lluis F, Bachs $O$ and Capella G (1998) Disruption of the antiproliferative TGF-beta signaling pathways in human pancreatic cancer cells. Oncogene 17: 1969-1978

24. Soni R, Muller L, Furet P, Schoepfer J, Stephan C, Zumstein-Mecker S, Fretz H and Chaudhuri B (2000) Inhibition of cyclin-dependent kinase 4 (Cdk4) by fascaplysin, a marine natural product. Biochem. Biophys. Res. Commun. 275 : 877-884

25. Becker TC, Noel RJ, Coats WS, Gomez-Foix AM, Alam T, Gerard RD and Newgard CB (1994) Use of recombinant adenovirus for metabolic engineering of mammalian cells. Methods Cell Biol. 43 (Part A): 161-189

26. Cascalló M, Mercade E, Capella G, Lluis F, Fillat C, Gomez-Foix AM and Mazo A (1999) Genetic background determines the response to adenovirus-mediated wild-type p53 expression in pancreatic tumor cells. Cancer Gene Ther. 6 428-436

27. Mayol X, Garriga J and Graña X (1995) Cell cycle-dependent phosphorylation of the retinoblastoma-related protein p130. Oncogene 11: 801-808

28. Garriga J, Limon A, Mayol X, Rane SG, Albrecht JH, Reddy EP, Andres V and Grana X (1998) Differential regulation of the retinoblastoma family of proteins during cell proliferation and differentiation. Biochem. J. 333 (Part 3): 645-654

29. Graña X, De Luca A, Sang N, Fu Y, Claudio PP, Rosenblatt J, Morgan DO and Giordano A (1994) PITALRE, a nuclear CDC2-related protein kinase that phosphorylates the retinoblastoma protein in vitro. Proc. Natl. Acad. Sci. USA 91: $3834-3838$
30. Garriga J, Segura E, Mayol X, Grubmeyer C and Grana X (1996) Phosphorylation site specificity of the CDC2-related kinase PITALRE. Biochem. J. 320 (Part 3): 983-989

31. Graña X, Garriga J and Mayol X (1998) Role of the retinoblastoma protein family, pRB, p107 and p130 in the negative control of cell growth. Oncogene 17: $3365-3383$

32. Cheng L, Rossi F, Fang W, Mori T and Cobrinik D (2000) Cdk2-dependent phosphorylation and functional inactivation of the pRB-related p130 protein in pRB(-), p16INK4A(+) tumor cells. J. Biol. Chem. 275: 30317-30325

33. Parreño M, Garriga J, Limon A, Albrecht JH and Grana X (2001) E1A modulates phosphorylation of $\mathrm{p} 130$ and $\mathrm{p} 107$ by differentially regulating the activity of G1/S cyclin/CDK complexes. Oncogene 20: 4793-4806

34. Parreño M, Garriga J, Limon A, Mayol X, Beck Jr GR, Moran E and Grana X (2000) E1A blocks hyperphosphorylation of p130 and p107 without affecting the phosphorylation status of the retinoblastoma protein. J. Virol. 74: 3166-3176

35. McConnell BB, Gregory FJ, Stott FJ, Hara E and Peters G (1999) Induced expression of p16(INK4a) inhibits both CDK4- and CDK2-associated kinase activity by reassortment of cyclin-CDK-inhibitor complexes. Mol. Cell. Biol. 19: 1981-1989

36. Vlach J, Hennecke S and Amati B (1997) Phosphorylation-dependent degradation of the cyclin-dependent kinase inhibitor p27. EMBO J. 16: 5334-5344

37. Cheng M, Olivier P, Diehl JA, Fero M, Roussel MF, Roberts JM and Sherr CJ (1999) The p21(Cip1) and p27(Kip1) CDK 'inhibitors' are essential activators of cyclin D-dependent kinases in murine fibroblasts. EMBO J. 18: 1571-1583

38. Tetsu $O$ and McCormick F (2003) Proliferation of cancer cells despite CDK2 inhibition. Cancer Cell 3: 233-245

39. Ortega S, Prieto I, Odajima J, Martin A, Dubus P, Sotillo R, Barbero JL, Malumbres $M$ and Barbacid $M$ (2003) Cyclin-dependent kinase 2 is essential for meiosis but not for mitotic cell division in mice. Nat. Genet. 35: 25-31

40. Sicinska E, Aifantis I, Le Cam L, Swat W, Borowski C, Yu Q, Ferrando AA, Levin SD, Geng Y, von Boehmer H and Sicinski P (2003) Requirement for cyclin D3 in lymphocyte development and T cell leukemias. Cancer Cell 4: $451-461$

41. Parisi T, Beck AR, Rougier N, McNeil T, Lucian L, Werb Z and Amati B (2003) Cyclins $\mathrm{E} 1$ and $\mathrm{E} 2$ are required for endoreplication in placental trophoblast giant cells. EMBO J. 22: 4794-4803

42. Weiss RH (2003) p21Waf1/Cip1 as a therapeutic target in breast and other cancers. Cancer Cell 4: 425-429

43. Suzuki A, Tsutomi Y, Miura M and Akahane K (1999) Caspase 3 inactivation to suppress Fas-mediated apoptosis: identification of binding domain with p21 and ILP and inactivation machinery by p21. Oncogene 18: 1239-1244

44. Dick FA and Dyson N (2003) pRB contains an E2F1-specific binding domain that allows E2F1-induced apoptosis to be regulated separately from other E2F activities. Mol Cell. 12: 639-649

45. Donnellan R and Chetty R (1999) Cyclin E in human cancers. FASEB J. 13: 773-780

46. Winters ZE, Leek RD, Bradburn MJ, Norbury CJ and Harris AL (2003) Cytoplasmic p21WAF1/CIP1 expression is correlated with HER-2/ neu in breast cancer and is an independent predictor of prognosis. Breast Cancer Res. 5: R242-9 